\title{
FIGURILLA FENICIA DE BRONCE DEL MUSEO "INSTITUTO GÓMEZ-MORENO" (GRANADA)
}

\author{
A BRONZE PHOENICIAN FIGURINE FROM THE INSTITUTO \\ GÓMEZ-MORENO MUSEUM (GRANADA)
}

\author{
por \\ EDUARDO GARCÍA ALFONSO
}

Entre el caudal bibliográfico, documental y material reunido por D. Manuel Gómez-Moreno(1870-1970) resulta notoria su colección arqueológica. Este material se conserva en su Granada natal, en el museo que lleva el nombre del insigne erudito, que ocupa un hermoso carmen emplazado en la colina de la Alhambra. Aquí, la Fundación Rodríguez-Acosta custodia el patrimonio que D. Manuel fue atesorando a lo largo de su vida y continúa su labor de investigación. Debido a que este legado estuvo durante años en el domicilio familiar de los Gómez-Moreno en Madrid, la pieza que traemos a colación ha pasado desapercibida para los estudiosos de la Protohistoria, a pesar de su interés dentro de la serie de bronces de carácter fenicio y orientalizante aparecidos en la Península Ibérica ${ }^{1}$ (García Alfonso y otros 1999: 224).

Se trata de una pequeña estatuilla masculina (fig. 1, lám. I), con una altura máxima de $155^{\prime} \mathrm{cm}$, en buen estado de conservación (Sánchez-Mesa 1992: 162, $\mathrm{n}^{\circ} .98$ ). El material es bronce macizo, con pátina parda y verdosa. La superficie muestra huellas de pequeñas vacuolas, que revelan su realización a la cera perdida, aunque los detalles se completaron a buril. El personaje adopta actitud de marcha, adelantando convencionalmente la pierna izquierda. Muestra unos pies descalzos mayores que el cañón de la figura, los cuales, bajo sus plantas, tienen sendas protuberancias-muy frecuentes en este tipo de piezas-que son el testimonio de los orificios para desalojar la cera del molde, además de servir para el anclaje de la pieza en algún tipo de soporte, hoy lógicamente perdido. En salutación ritual, levanta la mano derecha abierta, donde aún es más palpable la desproporción de su gran tamaño en relación con el conjunto. Al tiempo, dobla el brazo izquierdo en ángulo recto, con el puño cerrado y atravesado por un agujero longitudinal, que seguramente serviría para insertar un bastón. Las piernas presentan cierto desarrollo de los músculos gemelos, aunque

1. Museo Instituto Gómez-Moreno, $\mathrm{n}^{\circ}$ de inventario 152. Agradecemos a la Fundación Rodríguez-Acosta las facilidades dadas para el estudio de la pieza. No es éste el único bronce fenicio del que D. Manuel da noticia. En su documentación manuscrita cita otro similar procedente de Salobreña, que conserva incluso la "mitra" (sic) sobre la cabeza, refiriéndose a la lebbade -alto gorro cónico fenicio-o bien a la corona blanca del Alto Egipto hedyet. De esta pieza de la costa granadina Gómez-Moreno padre realizó un dibujo, que no hemos podido localizar. 
sin un tratamiento anatómico pormenorizado. El personaje se cubre con el típico faldellín corto egipcio o šendyit, muy ceñido, con escotadura en el lado izquierdo y sujeto por un cinturón inciso, que se remata en la parte frontal con una doble curva, a modo de flor de loto invertida, de un arte mediocre. El torso, desnudo, no muestra ningún detalle a excepción del ombligo, que se señala mediante una leve circunferencia incisa. La espalda es lisa. La figura descansa sobre una peana de madera, a la que está fijada con argollas metálicas, todo ello adición moderna.

Los rasgos más notables de la figura los encontramos en la cabeza, a la que su artífice ha prestado cierta atención. No posee cabello, mostrando unas orejas grandes y salientes. Los ojos, alargados y rasgados, se representan mediante dos incisiones superpuestas cada uno, que dejan un espacio cóncavo, rehundido para destacar las cejas. La nariz es saliente, formando línea con la frente, que es huidiza. La boca es amplia, con labios finos y estrechos, estando cerrada, pero en actitud ligeramente sonriente. Por último, presenta mentón saliente.

A ambos lados de la cabeza, en la parte superior de los parietales, aparecen dos pequeños remaches de bronce. Seguramente se trata del sistema de anclaje de algún tipo de tocado alto, hoy perdido, tipo lebbade o hedyet, realizado en un material distinto al bronce, quizás constituido por una lámina de oro y un alma de madera u otro material parecedero (fig. 2). Esta posibilidad no resulta extraña en el mundo de la pequeña estatuaria fenicia. Era necesario recurrir al remachado para sujetar con firmeza cualquier aditamento de otro metal distinto al de la figura, al no poder fundirse al mismo tiempo que ésta. Una vez que la pieza se había enfriado se procedía a efectuar un pequeño agujero mediante un taladro en el lugar donde se introduciría el remache. Una vez dentro, el vástago se fijaba vertiendo unas gotas de bronce fundido para llenar el agujero prácticado, que, al solidificarse lo mantenían sujeto. Así, en el mundo cananeo conocemos numerosos casos de estatuillas hechas en bronce que muestran añadidos de otro material, normalmente oro. Como ejemplos cabe citar el nutridísimo lote aparecido en el templo de los Obeliscos de Biblos, el Smiting God sin procedencia del Museo de Los Ángeles y el dios sedente hallado en el área BB de Megiddo (Negbi 1976: 156-157, $\mathrm{n}^{\circ}$. $530-702,162, \mathrm{n}^{\circ} .1307 ; 172, \mathrm{n}^{\circ}$. 1453). La combinación de dos metales no resulta desconocida en las producciones fenicias de la Península Ibérica, como demuestra el "sacerdote de Cádiz", con su máscara de oro (Perea 1991: 156-157). También se utilizó el remachado en ocasiones para asegurar los brazos, cuando éstos se añadían a las figuras después de haber elaborado el cuerpo. Esta técnica aparece ya plenamente atestiguada en el Bronce Tardío del Levante mediterráneo, como vemos en un Smiting God procedente de la "acrópolis" de Ugarit (Negbi 1976: 163, $\left.\mathrm{n}^{\circ} .1319\right)$. En el Extremo Occidente la encontramos en la estatuilla $n^{\circ} .2$ de Sancti Petri (Perdigones 1991: 1125, fig. 3) (lám. II) y en el bronce $n^{\circ} .1$ de la Barra de Huelva (Gamer-Wallert 1983: lám. 13) (lám. III). Estos aditamentos, incluso con remaches, constituían la parte más frágil de las estatuillas, por lo que en la mayoría de las piezas se han perdido, aunque los canales para insertarlos son testimonio de su existencia.

La procedencia del bronce del Instituto Gómez-Moreno es desconocida. En su tiempo perteneció a la colección que $\mathrm{D}^{\text {a }}$. Regla Manjón Mergelina, condesa de Lebrija, logró reunir en su palacio sevillano ${ }^{2}$. Según la documentación conservada en la Fundación Rodríguez-Acosta, el bronce fue adquirido a la citada aristócrata por D. Apolinar Rodríguez, quien lo regaló a Gómez-Moreno en fecha que no consta. Ante esto, pensamos que no es descabellado suponer que la estatuilla proceda de alguno de los numerosos yacimientos tartéssicos que rodean la ciudad hispalense, debiendo aparecer en un momento no precisado entre finales del siglo XIX y comienzos del XX. A propósito de lo dicho, no faltan en los alrededores de la capital andaluza piezas similares, también sin procedencia concreta, como el bronce Carriazo (Maluquer de Motes 1957), la Astarté

2. D. Eduardo de León y Manjón, actual conde de Lebrija, nos ha informado amablemente que en el archivo de $D^{a}$. Regla no existe ninguna referencia relativa a la pieza objeto de este trabajo. 
llamada "del Carambolo" (Blázquez 1975: 111-112) y el bronce de la Colección Vives ${ }^{3}$ (Almagro Basch 1980: 249-253) (lám IV).

El bronce del Museo Gómez-Moreno representa un tipo iconográfico bien conocido en el Levante: el personaje que levanta la mano derecha abierta en actitud de salutación ritual o bendición. Dicho ademán aparece en la religión cananea durante el Bronce Tardío ${ }^{4}$, pasando al mundo fenicio y púnico posterior. Lo conocemos en Ugarit a finales del siglo XIII a.C. en una estela en la que un monarca no identificado realiza una ofrenda al dios supremo $\mathrm{El}$ (Bunnens 1995). En el ámbito sirio-palestino de fines del segundo milenio el saludo ritual aparece ya en numerosas figuras de bronce, tanto masculinas como femeninas, de pie o sedentes. Se han documentado ejemplares en Ugarit, Biblos, Megiddo y Hazor (Negbi 1976: $\mathrm{n}^{\circ} .1434$, 1441,1443 y 1451), además de bastantes piezas de procedencia desconocida. Sin embargo, la iconografía exacta de la pieza del Instituto Gómez-Moreno no se documenta en el Levante durante el segundo milenio. No encaja en ninguno de los grupos individualizados en el corpus de O. Negbi, que sólo recoge el material de la Edad del Bronce. Este tipo es creación del artesanado fenicio del primer milenio a.C., donde lo egiptizante será uno de los rasgos más acusados (Moorey y Fleming 1984: 73-75). G. Falsone (1988: 90), que sistematiza la producción broncínea de la Edad del Hierro, incluye el tipo que nos ocupa en su grupo IIIB. Desde los asentamientos fenicios en el Mediterráneo central y occidental esta postura ritual influyó en los cultos indígenas vecinos. De este modo, encontramos bronces nurágicos con tiara alta y mano derecha levantada desde el siglo VIII a.C., como el procedente de La Nurra (Moscati 1975: 223, lám. 243). La misma actitud aparece también en numerosos exvotos ibéricos de bronce, aunque con una cronología mucho más tardía (Prados 1992: $\mathrm{n}^{\circ}$. 368, 370, 621-623, 637-338 y 665).

Como ocurre con otras manifestaciones del arte fenicio, conocemos mejor este tipo de figuras en el ámbito colonial que en la metrópoli. Uno de los pocos hallazgos con contexto arqueológico procede del templo de Astarté de Kition, en cuyo patio se documentaron dos pequeños bronces pertenecientes al denominado nivel 2a, fechado entre los años 800-600 (Karageorghis 1976: 111, lám. 89). Los bronces más tempranos de la serie conocidos en el sur de la Península Ibérica deben corresponder al siglo VIII. Pero, como han escrito R. Olmos (1992: 44) y M.E. Aubet (1994: 179-180), siguiendo a I. Gamer-Wallert, estamos ante tipos muy arcaizantes y conservadores, por lo que la iconografía permanece casi idéntica a lo largo de un considerable período de tiempo. En consecuencia, resulta muy difícil fechar unas piezas que suelen carecer de contexto arqueológico, ya que los criterios estilísticos sirven de poco. La datación de todas ellas se sitúa en los siglos VIII-VII a.C., aunque algunas se podrían situar en el siglo VI (Falsone 1988: 90). Desgraciadamente, los bronces fenicios que conocemos en España con este tipo de salutación ritual están todos incompletos, faltando precisamente la mano derecha, aunque en algunas figuras dicha actitud es evidente. En el caso de las figuras varoniles, piezas cercanas al bronce del Instituto Gómez-Moreno por su actitud de caminar e indumentaria son las estatuillas $\mathrm{n}^{\circ} .2$ (lám. II) y $\mathrm{n}^{\circ} .4$ de Sancti Petri (Perdigones 1991: figs. 3

3. Esta pieza consta en los archivos del Museo Arqueológico Nacional, donde ingresó en 1913, como hallada en Itálica. Dicha atribución puede descartarse por su tipología, claramente asignable al periodo fenicio arcaico. La explicación de esta errónea información se debe a la costumbre que tenían los anticuarios sevillanos de la época de señalar a la ciudad romana como origen de las piezas que vendían, a fin de asegurarse un mejor precio. La procedencia de la estatuilla de los alrededores de Sevilla parece segura (Almagro Basch 1980: 250).

4. El origen de este gesto es oscuro. En Egipto lo conocemos como salutación desde el Imperio Antiguo -mastaba de la princesa Idut en Saqqara-. A mediados de la dinastía XVIII, aunque sin despojarse de su carácter cotidiano, parece que adquirió un sentido más ritual y protocolario en algunos contextos. Así, lo encontramos en escenas de presentación del faraón a los dioses, como en la Capilla del Nacimiento del templo de Luxor -Amenofis III niño ante Amón- o en la puerta del segundo sepulcro de Tutankamón -el joven rey ante Osiris-. Con un sentido de jerarquía figura en una pintura de la tumba de Amenhotep-Huy, virrey de Kush, en Qurnet Mura, o en el relieve de la recepción de emisarios nubios por Ramsés II en el santuario de Beit el-Wali. Es sintomático que el mismo ademán aparezca en Canaán poco después del afianzamiento de la presencia egipcia en dicho territorio (Brunner 1977: 583-585). 
y 5) y el nº. 1 de la ría de Huelva (Gamer-Wallert 1983: lám. 13) (lám. III), aunque desgraciadamente todas están incompletas. Representan personajes que muestran una actitud de serenidad, alejada de la tensión del Smiting God. El bronce de la antigua colección Vives debe incluirse también en esta categoría de Peace Figurines, según la denominación de H. Seeden (1982). Esta figura incompleta fue restituida por M. Almagro Basch (1980: 249-253, láms. I-II) blandiendo una lanza en su mano derecha. Observando la estatuilla detenidamente podemos ver cómo el antebrazo derecho se ha roto algo más abajo del codo, pero se conserva lo suficiente para comprobar que el personaje levantaba un poco el mismo, mientras que el brazo permanece pegado al cuerpo. Todos los bronces que representan la iconografía de combate alzan verticalmente su brazo derecho, con una marcada separación del torso, en actitud de empuñar un arma. Por tanto, parece más lógico pensar que el bronce de la antigua Colección Vives realizara el saludo ritual (lám. IV).

Sobre la finalidad y el significado del bronce del Instituto Gómez-Moreno poco es lo que podemos decir, salvo su muy probable función religiosa. Puede ser un devoto, un sacerdote o una divinidad. D. Ciafaloni (1995: 547) sostiene que la presencia de la corona, símbolo de soberanía y de inmortalidad, y el gesto de bendición, que define una naturaleza paternal y protectora, son atributos de Báal. Con este argumento, pero con las necesarias reservas, nos inclinamos por la última posibilidad. Bien pudiera tratarse de alguno de los numerosos y mal conocidos $B a$ álimm, como creemos ocurre con otros bronces que no encajan en la iconografía habitual de los grandes dioses del panteón fenicio, por otro lado tan poco definida y tan polivalente. Los pocos hallazgos con contexto arqueológico seguro o más o menos conocido indican que estas estatuillas proceden de favissae situadas en el interior o en los alrededores de los santuarios. Otro caso serían las piezas aisladas rescatadas del mar en lugares aparentemente sin ninguna vinculación religiosa, como Selinunte, que deben atribuirse más a naufragios que a ofrendas arrojadas a las aguas en cumplimiento de un voto (Aubet 1994: 179). En este sentido, algunos autores han querido ver en los pequeños bronces un testimonio del culto público, lo que coincidiría con su hallazgo en depósitos de ofrendas en los templos, mientras que las pequeñas figuras de terracota corresponderían al ámbito de la piedad personal (Moorey y Fleming 1984: 77-78). En conexión con esta idea habría que señalar cómo el tipo del Smiting God apenas si se documenta en terracota, como corresponde a una divinidad de corte oficial. Mientras las Peace Figurines gozan de gran estima como elementos de veneración privada, tanto doméstica como funeraria, sin que ello les quite protagonismo en el ceremonial de los grandes santuarios.

\section{BIBLIOGRAFÍA}

AUBET, M.E. (1994): Tiro y las colonias fenicias de Occidente. Edición ampliada y puesta al día. Barcelona. ALMAGRO BASCH, M. (1980): "Un tipo de exvoto de origen orientalizante", Trabajos de Prehistoria 37: 247-289.

BLÁZQUEZ, J.M. (1975): Tartessos y los orígenes de la colonización fenicia en Occidente. Salamanca. BRUNNER, E. (1977): “Gesten”, Lexikon der Ägyptologie, vol. II. Wiesbaden: 573-585.

BUNNENS, G. (1995): "The So-Called Stele of the God El from Ugarit", Actes du III Congrès International des Études Phéniciennes et Puniques (Túnez, 1991), vol. I: 214-221.

CIAFALONI, D. (1995): “Iconographie et iconologie”, V. Krings (ed.): La civilisation phénicienne et punique. Manuel de Recherche. Leiden: 535-549.

FALSONE, G. (1988): "La Fenicia come centro di lavorazione del bronzo nell'età del Ferro", Dialoghi di Archeologia 6 ( $3^{\text {a }}$ serie): 79-110.

GAMER-WALLERT, I. (1983): “Zwei Statuetten syro-ägypticher Gottheiten von der «Barra de Huelva»”, Madrider Mitteilungen 23: 46-61. 
GARCÍA ALFONSO, E.; MARTÍNEZENAMORADO, V. y MORGADO RODRÍGUEZ, A. (1999), Museos Arqueológicos de Andalucía, vol. II. Málaga.

KARAGEORGHIS, V. (1976): Kition. Mycenaean and Phoenician Discoveries in Cyprus. Londres.

MALUQUER DE MOTES, J. (1957): "De metalurgia tartésica: el Bronce Carriazo", Zephyrus 8: 157-168.

MOOREY, P.R.S. y FLEMING, S. (1984): "Problems in the Study of the Anthropomorphic Metal Statuary from Syro-Palestine before 330 b.C.", Levant 16: 67-90.

MOSCATI, S. (1975): "Los fenicios en Occidente", Los fenicios. La expansión fenicia. Cartago. Madrid: 143-257.

NEGBI, O. (1976): Canaanite Gods in Metal. Tel Aviv.

OLMOS, R. (1992): "Broncística fenicia y orientalizante en el sur peninsular y en Ibiza. Una aproximación iconográfica y simbólica", Producciones artesanales fenicio-púnicas. VI Jornadas de Arqueología Fenicio-Púnica (Ibiza, 1991): 41-64.

PEREA, A. (1991): Orfebrería prerromana. Arqueología del oro. Madrid.

PERDIGONES, L. (1991): "Hallazgos recientes en torno al santuario de Melkart en la isla de Sancti Petri (Cádiz)", Atti del II Congresso Internazionale di Studi Fenici e Punici (Roma, 1987), vol. III: 1119-1132.

PRADOS, L. (1992): Exvotos ibéricos de bronce del Museo Arqueológico Nacional. Madrid.

SÁNCHEZ-MESA, D. (1992): "Escultura", Instituto Gómez-Moreno. Granada: 59-76.

SEEDEN, H. (1982): "Peace Figurines from the Levant", Archéologie au Levant. Recueil à la memoire de R. Saidah. Lyon: 107-120. 


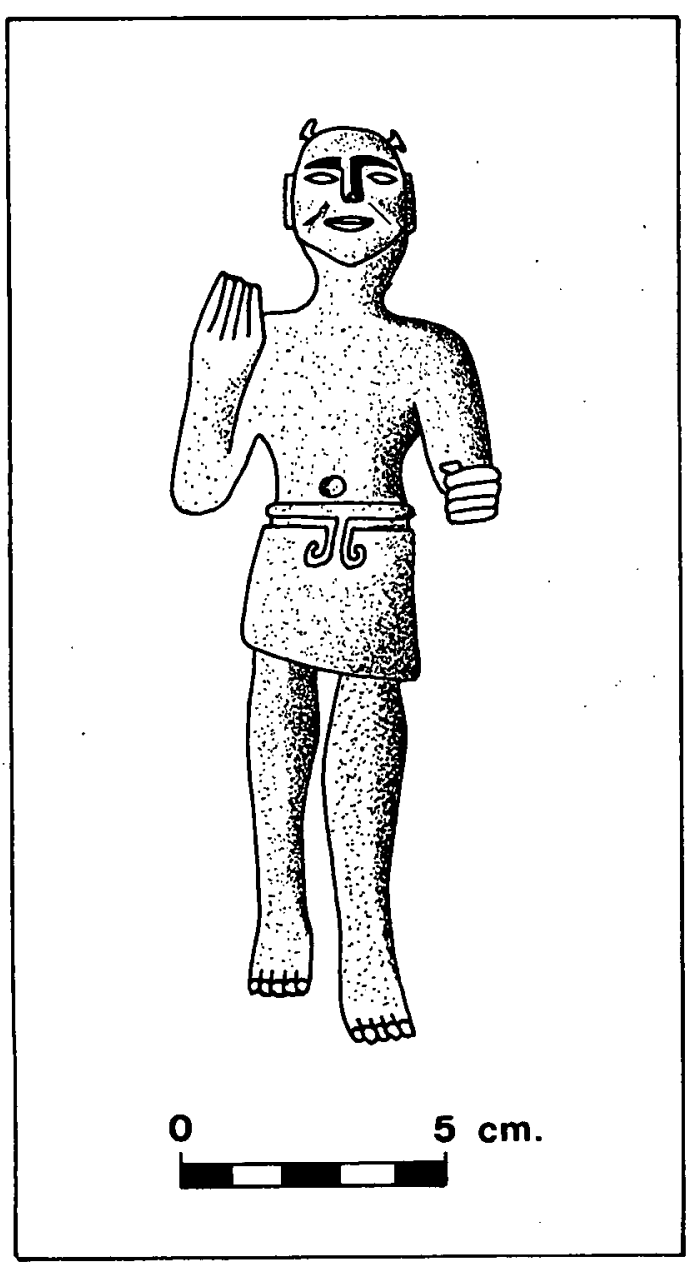

Fig. 1. Bronce del Museo Instituto Gómez-Moreno. Granada

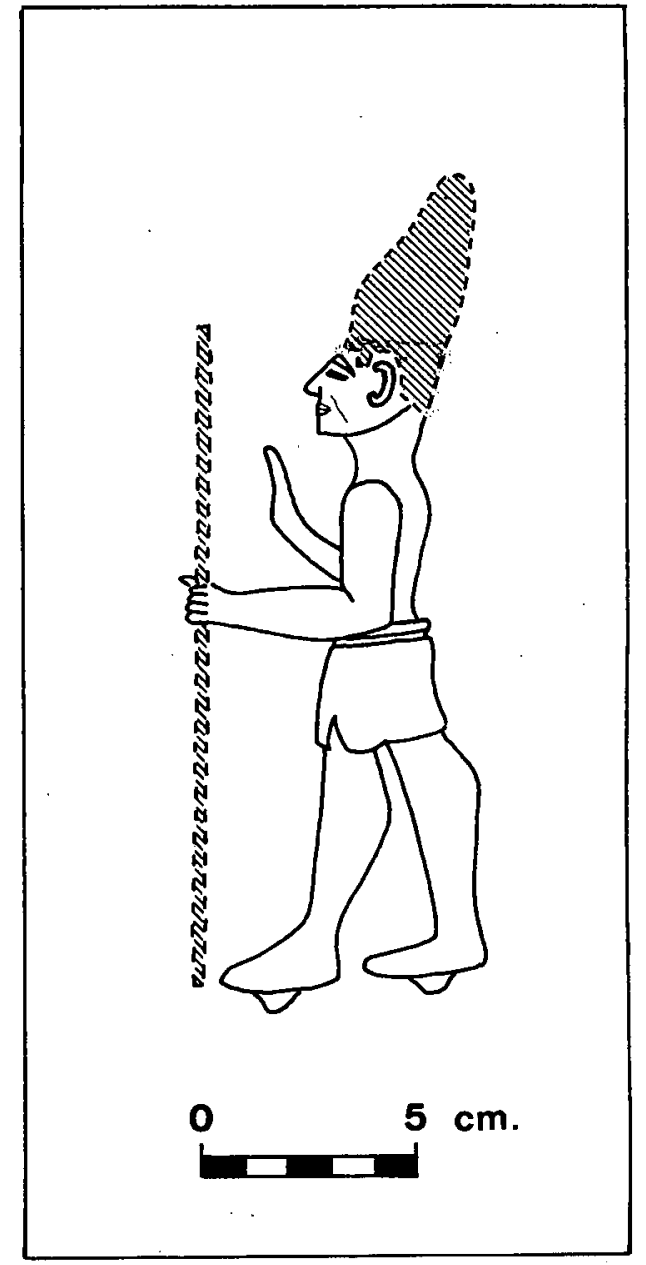

Fig. 2. Reconstrucción hipotética del bronce Instituto Gómez-Moreno.

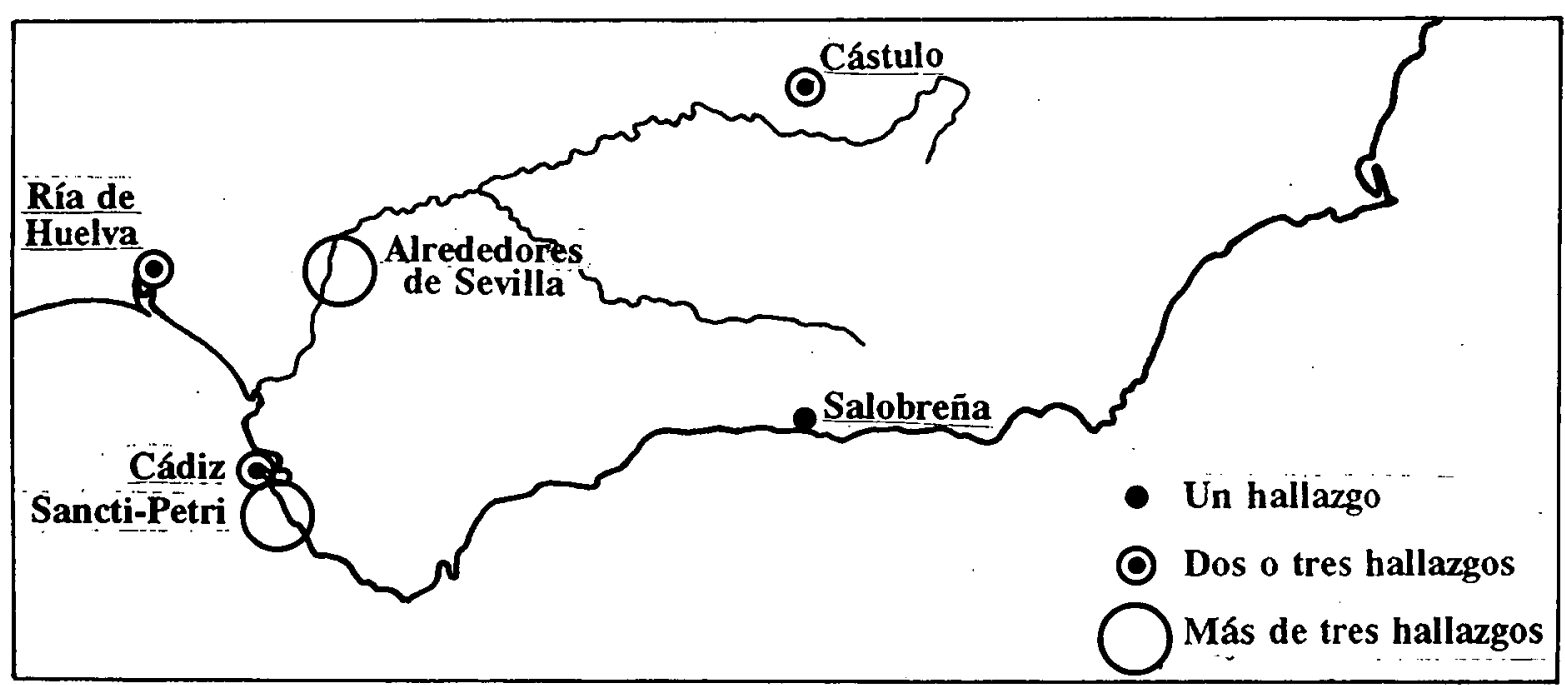

Fig. 3. Dispersión de los bronces fenicios y orientalizantes en el sur peninsular. 


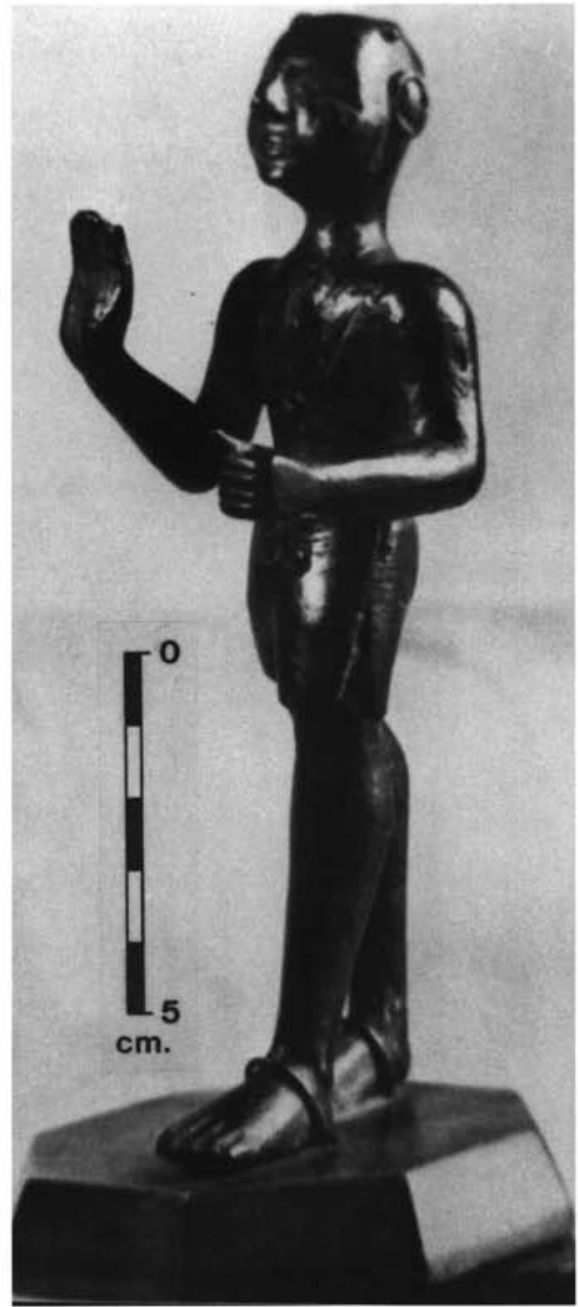

Lám. I. Bronce del Museo Instituto Gómez-Moreno, Granada (fot. Fundación Rodríguez-Acosta) 


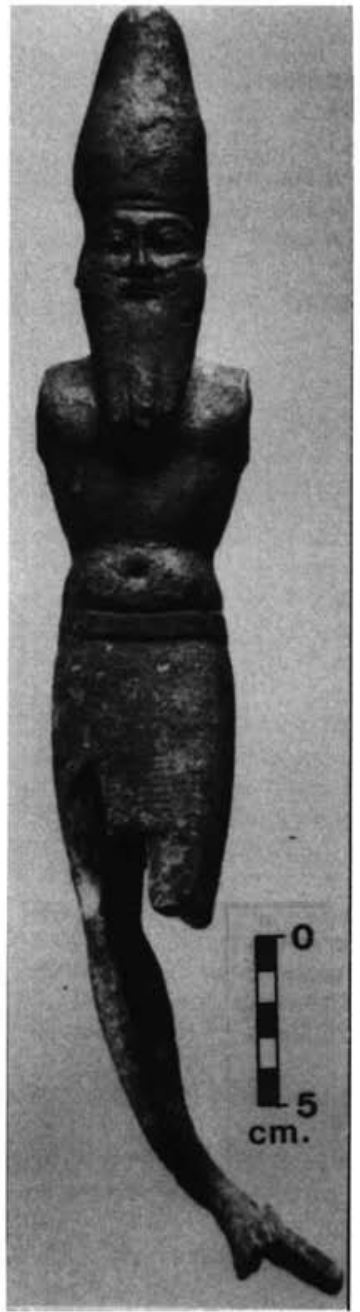

Lám. II. Bronce $\mathrm{n}^{\circ} .2$ de Sancti-Petri. Museo de Cádiz. (fot. L. Perdigones) 


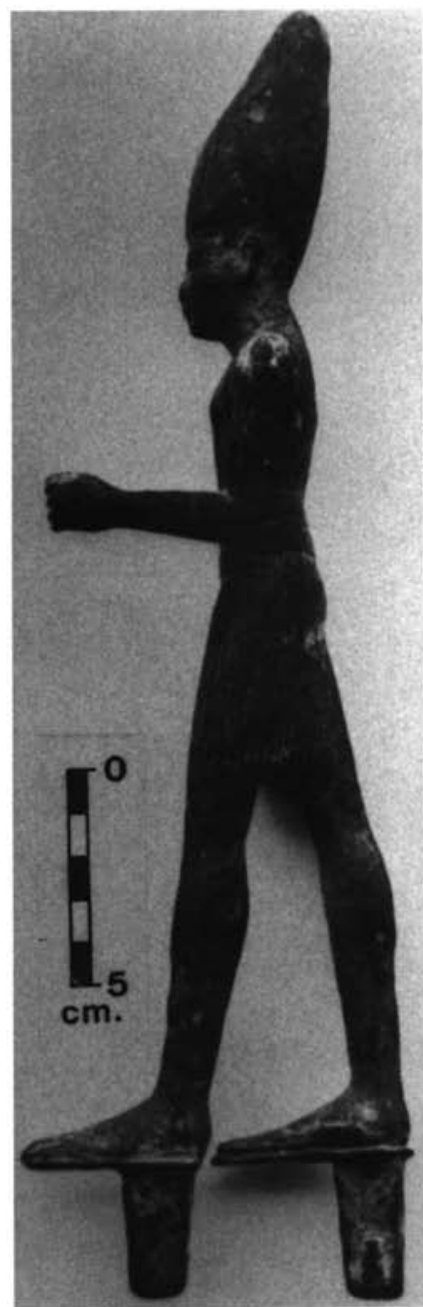

Lám. III. Estatuilla n. 1 de la ría de Huelva. Colección particular (fot. D.A.I., P. Witte). 


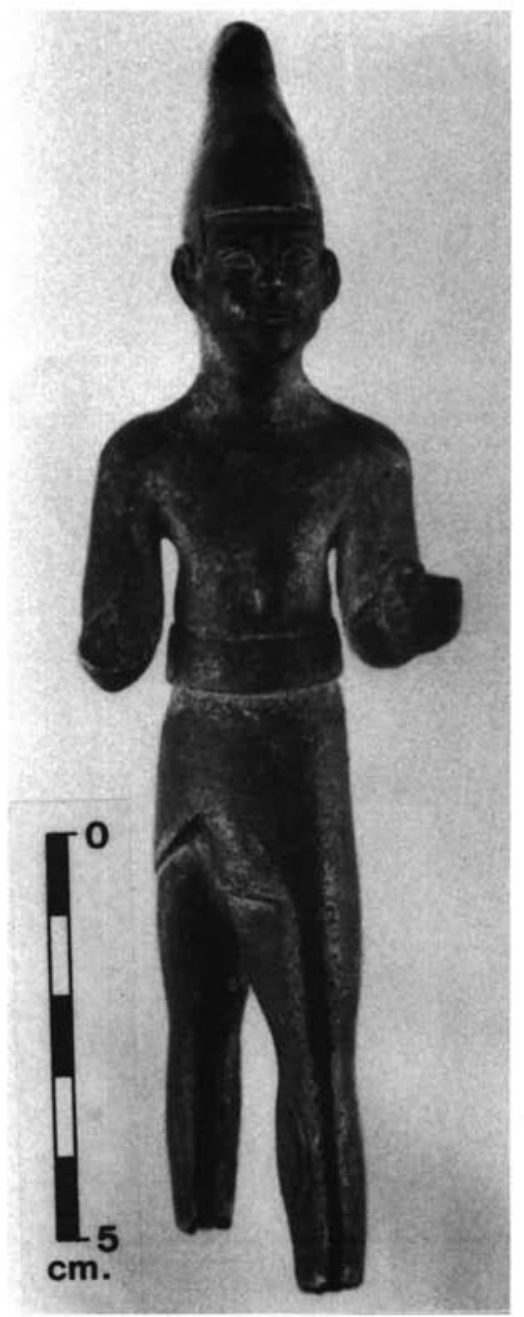

Lám. IV. Bronce de la antigua Colección Vives. Museo Arqueológico Nacional (fot. C.S.I.C., M. Almagro Basch), 